\title{
Social Inequality and System-Justifying Function of Compensatory Judgments in Person Perception*,\#
}

\author{
Naoya Yada, Tomoko Ikegami \\ Department of Psychology, Osaka City University, Osaka, Japan \\ Email: yaday708@gmail.com
}

How to cite this paper: Yada, N., \& Ikegami, T. (2017). Social Inequality and System-Justifying Function of Compensatory Judgments in Person Perception. Psychology, 8, 2031-2046.

https://doi.org/10.4236/psych.2017.812130

Received: September 12, 2017

Accepted: October 23, 2017

Published: October 26, 2017

Copyright $\odot 2017$ by authors and Scientific Research Publishing Inc. This work is licensed under the Creative Commons Attribution International License (CC BY 4.0).

http://creativecommons.org/licenses/by/4.0/

\section{Open Access}

\begin{abstract}
This study addressed the system-justifying function of compensatory judgments in person perception. We hypothesized that compensatory judgments of competence and warmth would create an illusion of equality, thereby fulfilling system-justifying motives in the economically unequal society. An experimental vignette study was conducted with 188 Japanese university students. Results indicated that evaluating target persons in a compensatory manner enhanced the perceived legitimacy of the current social system when participants were led to believe that a significant economic gap exists in Japan between the rich and the poor. This suggests that compensatory judgments serve to system justification through restoring the impaired belief in equality. We discussed the implications of our results for system justification theory and the literature on compensation effects in social judgments.
\end{abstract}

\section{Keywords}

Person Perception, Competence, Warmth, Compensatory Judgments, System Justification, Economic Disparity

\section{Introduction}

Numerous studies have investigated the psychological mechanisms that determine how impressions of others are formed. In recent years, the compensatory judgment in person or group perception has received much attention. Although individuals or groups are evaluated on various trait dimensions, there is sub-

\footnotetext{
${ }^{*}$ The present research was supported by the grant in aid that the second author received from the Japan Society for Promotion of Science (H1503448).

\#Part of the present research was presented at the $53^{\text {rd }}$ Annual Meeting of Japanese Society of Social Psychology.
} 
stantial agreement that these trait dimensions converge into two fundamental dimensions: competence and warmth (e.g., Rosenberg, Nelson, \& Vivekananthan, 1968; Fiske et al., 2007; for a review, see Cuddy, Fiske, \& Glick, 2008). Interestingly, judgments based on these two fundamental dimensions are likely to fall into a compensatory pattern (i.e., targets are evaluated high on one dimension and low on the other) (Judd, James-Hawkins, Yzerbyt, \& Kashima, 2005; Yzerbyt, Kervyn, \& Judd, 2008). However, this is not always the case. Early work on person perception revealed that competence and warmth were positively related to each other (i.e., halo effect or non-compensation) (Rosenberg et al., 1968). In addition, Judd et al. (2005) demonstrated that, while perceivers who observed only one target (individual or group) judged the target in a non-compensatory manner, perceivers who observed two targets contrasted on either of one dimension judged the targets in a compensatory manner.

Moreover, it was demonstrated that a compensatory judgment occurs even in the single target condition if perceivers compared the target to themselves. For example, Yada and Ikegami (2010) showed that their participants evaluated a target person who was perceived as more competent than themselves as less warm than the target perceived as less competent than themselves. Prior to these studies, it was also demonstrated that, while perceivers judged a target person who was more competent than themselves as less warm than themselves, they judged the less competent target as warmer than themselves (Ikegami, 2006). Although these studies only addressed how impressions about competent or incompetent target persons were formed, it is inferred that the perception of the target's superiority or inferiority in a certain dimension might lead perceivers to balance it in another dimension. Little is known, however, about why such mechanisms operate when forming impressions of others.

Yada and Ikegami $(2010 ; 2012 ; 2014)$ explored the conditions under which compensatory judgments of a competent or incompetent person on the warmth dimension are triggered, with a focus on the mediating role of social comparison-based emotions: admiration, envy, contempt, and pity (Smith, 2000). Yada and Ikegami (2014) predicted, based on Smith's (2000) characterization of each of the social comparison-based emotions, that envy (which motivates one to find reasons to dislike the advantaged person to justify one's own ill will) and pity (which motivates one to elevate the disadvantaged person in some important dimension as a sort of remedy) instigate compensatory judgments about the target perceived as superior and inferior on the competence dimension, respectively. As a result, whereas pity had no effect on evaluations of the incompetent target, envy toward the competent target increased the compensation effect. Given that envy is evoked by experiences of both the target's superiority and one's own inferiority (Smith, 2000), envy may be associated with the maintenance or defense of self-esteem. If this were the case, part of the compensation effect in person perception could be explained in terms of self-evaluation maintenance. However, even after partialling out the impact of envy, the target's competence had a direct 
and negative effect on the perceived warmth. Moreover, elevating an evaluation of the incompetent target's warmth cannot be explained by such self-enhancement motives, because within this self-evaluation maintenance framework it is predicted that people perceive themselves as both more competent and warmer than others. From these, one may argue that there is another factor besides such individualistic self-esteem motives that determines the occurrence of compensatory judgments. Thus, the current study focuses on a societal-level rather than an individual-level motive from the perspective of system justification theory, which contends that people sometimes prioritize societal motives at the sacrifice of individual or group-level interests (Jost \& Banaji, 1994).

\subsection{System Justification Theory}

The basic tenet of system justification theory (Jost \& Banaji, 1994; Jost, Banaji, \& Nosek, 2004) is that there is a general psychological tendency to justify and rationalize the status quo; that is, there is a motive to view the system to which one belongs as good, fair, legitimate, and desirable. In fact, a number of experimental studies revealed that people defend and bolster the legitimacy of the current social system following exposure to various manipulations of system threat (Jost, Kivetz, Rubini, Guermandi, \& Mosso, 2005; Kay, Jost, \& Young, 2005). This motive is deemed to stem from such fundamental needs as epistemic needs to attain certainty, consistency, and meaning, as well as existential needs to reduce threat and distress, which all humans possess in varying degrees (Jost, Glaser, Kruglanski, \& Sulloway, 2003; Jost \& Hunyady, 2005; Hennes, Nam, Stern, \& Jost, 2012). The system justification motive comes into play regardless of whether or not one strongly identifies with (or feels strongly attached to) the society to which he/she belongs. Kay, Gaucher, Peach, Laurin, Friesen, Zanna, and Spencer (2009) demonstrated that a mere perception of the fact that one's outcomes were dependent on a particular overarching system and that it was difficult to exit the system increased the desire to legitimize the social system. It was also assured that such perceptions did not affect one's personal and collective self-esteem (Laurin, Shepherd, \& Kay, 2010); just living in a society is enough to motivate people to justify the current status of that society.

\subsection{System-Justifying Function of Complementary Stereotypes: Illusion of Equality}

One sometimes experiences a conflict between a system justification motive and one's personal values. If the current social system (e.g., capitalism, liberal economy) causes inequality, the system justification motive will conflict with the egalitarian worldview. Kay and his colleagues argued that complementary stereotypes, which imply that that all groups or individuals have both advantages and disadvantages (i.e., one is superior on a certain dimension, but inferior on another) will mitigate such conflicts by creating the illusion of equality, thus 
enabling people to justify the current social system. In other words, when one is aware that there is a significant disparity between two social targets (i.e., $\mathrm{A}$ is superior to B) on a certain aspect (e.g., wealth or competence), the activation of complementary stereotypes leads to the idea that this difference between these two targets is reversed or balances out (i.e., B is superior to A) on other dimensions (e.g., happiness or morality) and that, as a consequence, they are leveled out. Accordingly, complementary stereotypes encourage us to perceive the current social system as just and legitimate by creating an illusion of equality (e.g., Jost et al., 2005; Kay \& Jost, 2003; Kay et al., 2005; for a review, see Kay, Jost, Mandisodza, Sherman, Petrocelli, \& Johnson, 2007).

In support of this argument, some studies have provided empirical evidence for the system-justifying function of complementary stereotypes. Kay and Jost (2003) demonstrated that their American participants who were presented with a complementary exemplar (i.e., "one is poor, but happy" and "the other is rich, but unhappy") rated the legitimacy of the current American society higher than their counterparts who were presented with a non-complementary exemplar (i.e., "one is poor and unhappy" and "the other is rich and happy"). Furthermore, Kay et al. (2005) showed that system threat (e.g., participants were told that "Many countries in the world are enjoying better social, economic, and political conditions than the United States") led people to rate the powerful people as more intelligent, but less happy, than the powerless, and the obese people as lazier, but more sociable, than normal weight people, in line with complementary stereotypes. Jost et al. (2005) demonstrated that the perceived magnitude of inequality in economy between two regions (North vs. South) was associated with increased stereotyping such that high-status regional group members were more agentic, but less communal, than low-status regional group members, which in turn was associated with a higher level of perceived legitimacy and stability of the system. However these studies may have latent limitations. One should note that the messages used in Kay et al. (2005) did not refer to or comment on the issues of inequality in the current society. The findings by Jost et al. (2005) were based on the correlational data. It therefore remained unclear whether participants were actually motivated to create an illusion of equality (to restore their sense of equality) through activating the complementary stereotypes and, hence, were making compensatory judgments. Thus the present research made an attempt to directly address this issue by experimentally manipulating the level of threat to equality in society.

\subsection{Compensatory Judgments in Person Perception and System Justification}

From the studies mentioned above, one could argue that compensatory judgments, in which a competent person is perceived as less warm and an incompetent person as warmer, occur as a result of the application of complementary stereotypes driven by the system justification motive. In other words, if the tar- 
get is superior to others (including the perceiver) in terms of competence, the target's high competence might be interpreted as a virtue. Conversely, if the target is inferior in terms of competence, the target's low-competence might be interpreted as a vice. Judging the target's warmth in a direction opposite to their competence means attributing a vice (i.e., low warmth) to a target who has a virtue (i.e., high competence) and a virtue (i.e., high warmth) to a target who has a vice (i.e., low competence). Thus, one may say that compensatory judgments in person perception are a process of confirming the belief that groups or individuals have both advantages and disadvantages by actively creating social targets consistent with complementary stereotypes. By so doing, perceivers possibly strengthen their belief in equality and then their sense of legitimacy of the current social system to which they belong. If compensatory judgments have such system-justifying functions, they are more likely to occur and have stronger effects on the perceived legitimacy of the status quo, particularly when one's egalitarian worldview is being threatened.

\subsection{The Present Research}

In order to test the notion described above, we conducted an experimental study with Japanese undergraduates, in which participants read a fictional article commenting on the economic gap in Japan to manipulate the levels of threat to their beliefs in equality and then evaluated a target person depicted as academically competent or incompetent on the two fundamental dimensions of competence and warmth. We hypothesized that, when exposed to a threat to equality, participants are motivated to defend and maintain their belief in equality, and consequently are more likely to evaluate the targets in a compensatory manner. Moreover, in such a situation, compensatory judgments are predicted to more prominently exert the system-justifying function.

One should note that the tendency of compensatory judgments could be assessed in two ways (Judd et al., 2005). The first is to assess the tendency that the target who is perceived as superior to the other on one dimension is judged as inferior to the other on another dimension (i.e., between-target compensation effect). The second is to assess the tendency that the higher the target is rated on one dimension, the lower the same target is evaluated on another (i.e., within-target compensation effect). Since the present research addressed the compensatory judgments in the single target situation, we employed the second measure (within-target compensation effect) to test the hypothesis below.

Our hypotheses are described below:

Hypothesis 1: Perceivers are more likely to make a compensatory judgment about (in)competent individuals in terms of warmth when exposed to a significant (vs. insignificant) rich-poor economic gap in Japanese society.

Hypothesis 2: Compensatory judgments more strongly exert a system-justifying function when exposed to a significant (vs. insignificant) rich-poor economic gap in Japanese society. 
To verify the Hypothesis 1, we will compare the magnitude of within-target compensation effects (the tendency that the more competent the target is evaluated, the less warm the same target is evaluated) between the two experimental conditions, to see if the effect will be greater in the condition that poses a threat to the equality (high equality-threat condition) than in the one that poses no such threat (low equality-threat condition). To verify the Hypothesis 2, we will examine if it happens that the more the participants evaluate the target in a compensatory manner, the more they perceive their societal system as legitimate only in the high equality-threat condition. We will conduct a three-way mixed ANOVA and a three-way GLM analysis for testing Hypothesis 1 and 2, respectively.

\section{Method}

\subsection{Participants and Design}

One hundred and eighty-eight Japanese undergraduates (94 men and 94 women) participated in the study on a voluntary basis. All participants were recruited among students who were enrolled in introductory psychology courses at Osaka City University without screening. Their average age was 18.57 years $(S D=$ 0.80 ). This study used a 2 (threat to belief in equality: high vs. low) x 2 (target competence: high vs. low) factorial design. The participants were randomly assigned to one of these four experimental conditions. We decided to assign at least 20 participants to each of the two experimental conditions based on conventional practices of experimental studies and to collect as many observations as we could in one class. Fifteen participants were eliminated because of missing values: Five participants were eliminated from the high-threat/high-competence target condition, two from the high-threat/low-competence target condition, and eight from the low-threat/low-competence target condition. Accordingly, the final sample consisted of 173 participants ( 86 men and 87 women). The average age of the final sample was 18.56 years $(S D=0.77)$. Thirty-one participants were assigned to the high-threat/high-competence target condition, thirty-six to the high-threat/low-competence target condition, fifty-seven to the low-threat/ high-competence target condition, and forty-nine to the low-threat/low-competence target condition.

\subsection{Procedure}

The study was administered in an anonymous mass-testing situation after class and all participants completed one of four versions of the questionnaires simultaneously. The first version contained a high equality-threat article combined with a high-competence target description, the second version contained a high equality-threat article combined with a low-competence target description, the third one contained a low equality-threat article with a high-competence target description, and the forth contained a low equality-threat article with a low-competence target description. Prior to asking undergraduates to fill in the 
questionnaire, we told them both orally and in writing (on the cover sheet) that participation in the experiment was on a voluntary basis. Only those who agreed were asked to indicate their gender, age, and nationality on the cover sheet.

\subsubsection{Manipulation of Levels of Threat to Equality}

The participants read one of two fictional articles that consisted of a paragraph with two graphs depicting the current socioeconomic condition in Japan. In the high-threat condition, the article stated that the economic disparity in Japan was expanding yearly and was much wider than in other countries. In the low-threat condition, the article stated that the economic disparity in Japan was decreasing yearly and was narrower than other countries. We devised this method to alter the participants' perception of the current economic situation with reference to the study by Kraus, Piff, and Keltner (2009). The participants then answered three manipulation check items. They indicated the degree to which they felt: a) the article was convincing (i.e., article credibility); b) the economic gap in Japan was expanding (i.e., gap expansion); and c) Japan was relatively equal (perceived equality) on a seven-point scale ranging from 1 (strongly disagree) to 7 (strongly agree).

\subsubsection{Measurement of Compensatory Judgments}

After manipulating the level of threat to equality in Japan, we conducted an impression formation task. Two types of descriptions were constructed on the basis of Yada and Ikegami's (2012) pilot study. In their pilot study, 46 undergraduates (18 male and 28 female) were asked to judge each of eighty behaviors on competence and warmth on a nine-point scale. Based on the mean for each behavior on each dimension that they calculated, we selected the behaviors that scored higher than 6 or lower than 4 on competence and scored between 4 and 6 on warmth as competence-related descriptions, and those that scored higher than 6 or lower than 4 on warmth and scored between 4 and 6 on competence as warmth-related descriptions. We also identified behaviors whose scores did not differ substantially from the midpoint (i.e., ranged between 4 and 6) on either of the two dimensions as neutral descriptions. As a result, the high-competence target description consisted of seven high-competence, two high- and two low-warmth, and one neutral behaviors, whereas the low-competence target description consisted of seven low-competence, two high- and two low-warmth, and one neutral behaviors. The warmth-related and neutral behaviors were identical across the high-competence and low-competence target conditions. The participants read one of the two descriptions about an academically competent (high-competence) or incompetent (low-competence) undergraduate student. They then made comparative judgments regarding competence and trait-descriptiveness ratings of the target based on competence and warmth. In comparative judgment, the participants answered the question "Who do you think is more competent, you or the target?" They were given two terms (excellence and competence) and indicated their responses on a seven-point scale ranging from 1 (I am far superior 
to the target) to 7 (the target is far superior to me). The scale midpoint (4) meant that participants perceived the target as equal to themselves. This was done to ensure that upward or downward comparison with respect to competence actually occurred. Next, the participants were given 20 trait terms and asked to indicate the extent to which each trait described the target person on a nine-point scale ranging from 1 (not at all descriptive) to 9 (very descriptive). Of the 20 trait terms, ten were relevant to competence $(\alpha=0.96)$, where five were positively denoted (efficient, wise, sensible, competent, and intelligent) and five were negatively denoted (inefficient, foolish, thoughtless, incompetent, and unintelligent). The remaining ten trait terms were relevant to warmth $(\alpha=0.89)$, where five were positively denoted (kind, warm, good-natured, considerate, and friendly) and five were negatively denoted (unkind, cold, ill-natured, inconsiderate, and unfriendly). These trait words were taken from the study by Yzerbyt et al. (2008) and modified for the current research.

\subsubsection{Measurement of Perceived Legitimacy of the Current Japanese Social System}

Finally, the participants completed the Japanese version of the diffuse system justification scale that was originally developed by Kay and Jost (2003). We modified the wording of some of the items to suit the Japanese context ( $\alpha=0.71$, $M=3.17, S D=0.80) .{ }^{1}$ The scale included eight questions regarding diffuse systems such as "In general, you find society to be fair" and "Japanese society needs to be radically restructured" (reverse scored). The participants were asked to indicate the extent to which they agreed with each statement on a seven-point scale ranging from 1 (strongly disagree) to 7 (strongly agree). This scale "is designed to capture differences in people's explicitly stated confidence in the status quo and is not a measure of motive or one's desire to justify the system" (Cutright, Wu, Banfield, Kay, \& Fitzsimons, 2011: 67). Accordingly, the ratings on this scale could be interpreted as reflecting whether or not the participants believe in the legitimacy of the current social system after reading the above fictional articles which enhanced or lowered the level of threat to equality.

\subsubsection{Debriefing}

Upon completion of the questionnaire, the participants were fully debriefed and thanked for their participation. In the debriefing, we explained the true purpose of the research and apologized for including fictional articles and target descriptions in the questionnaire.

\section{Results}

\subsection{Manipulation Checks}

\subsubsection{Perceived Gap Expansion and Equality}

To examine whether the manipulation of the levels of threat to equality of Japa-

${ }^{1}$ We devised the Japanese version of the scale for use with permission from the author, Prof. John, T. Jost. 
nese society was effective, a 2 (equality-threat condition: high vs. low) $\times 2$ (target competence: high vs. low) analysis of variance (ANOVA) was conducted on each of these scores. These ANOVAs showed that only the main effects of the threat condition were significant for ratings of gap expansion $(F(1,169)=22.88, p<$ $\left.0.001, \eta_{p}^{2}=0.119\right)$ and perceived equality $\left(F(1,169)=5.85, p=0.017, \eta_{p}^{2}=\right.$ 0.033). Participants assigned to either of the high and low target competence conditions perceived a greater gap expansion and less equality in the high relative to the low threat condition. These results confirmed that the manipulation of the level of equality-threat was successful.

\subsubsection{Comparative Judgment on Competence}

Two relevant items for comparative judgment on competence were averaged because they are highly correlated: $r=0.88, p<0.001$. We performed a 2 (equality-threat condition: high vs. low) $\times 2$ (target competence: high vs. low) ANOVA on the comparative judgment scores and found only a main effect of the target condition to be significant: $F(1,169)=331.87, p<0.001, \eta_{p}^{2}=0.663$. No other effects or interactions were significant: all $F \mathrm{~s}(1,169)<0.025, n s$. To ensure that participants perceived the target as more competent than themselves in the high-competence condition and as less competent than themselves in the low-competence condition, we compared this score with the scale midpoint (i.e., 4) for the high- and low-competence target conditions separately. This revealed that the high-competence target was rated as significantly higher (i.e., more competent) than the scale midpoint $(M=5.91, t(87)=16.17, p<0.001$, Cohen's $d=1.723$ ) and the low-competence target as significantly lower (i.e., less competent) than the scale midpoint $(M=3.00, t(84)=-9.99, p<0.001$, Cohen's $d=$ $-1.084)$. These results confirmed that the manipulation of target competence worked appropriately regardless of the equality-threat conditions.

\subsection{Testing Hypothesis}

To test our hypotheses, we first created a measure of the within-target compensation, as described earlier, by first subtracting the scale midpoint (i.e., 5) from each of the scores on perceived competence and warmth, multiplying these two scores, and finally multiplying this product by -1 . This turned out to be an index such that the magnitude of positive value indicates a stronger tendency of compensatory judgment, while the magnitude of negative value indicates a stronger tendency of non-compensatory judgment.

\subsubsection{Testing Hypothesis 1}

We hypothesized that people are more likely motivated to make compensatory judgment in person perception when their beliefs in equality of their society are being threatened. We therefore predicted that the amount of occurrence of compensatory judgments would be greater in the high-threat relative to low-threat condition. Therefore the within-target compensation measure described above was subjected to a 2 (equality-threat condition: high vs. low) $\times 2$ (target compe- 
tence: high vs. low) two-way ANOVA. However, no significant effects were observed. Thus, we could not obtain supportive evidence for Hypothesis 1.

\subsubsection{Testing Hypothesis 2}

We hypothesized that people are more inclined to rely on or utilize the system justifying function of compensatory judgments, namely the function of creating an illusion of equality, when they are faced with the threatening fact that a significant inequality exists in the current society. We therefore predicted that the positive relationship between the tendency of compensatory judgments and the perceived legitimacy of the current social system becomes more salient in the unequal than in the equal (control) society. We tested this idea by analyzing the within-target compensation effects. The measure of perceived legitimacy of Japanese society was subjected to a three-way general linear model (GLM) analysis that included the equality-threat condition and the target condition as categorical variables, the measure of the within-target compensatory judgment (centered on the grand mean) as a continuous variable. This analysis revealed a significant two-way interaction effect between the equality-threat condition and the compensatory judgment: $F(1,165)=6.39, p=0.012, \eta_{p}^{2}=0.037$ (Figure 1). The simple effects of the compensatory judgment were tested in each equality-threat condition (Figure 1). In the high threat condition, those who were high on a measure of the compensatory judgment rated the legitimacy of the current society $(M=3.36, S E=0.13)$ higher than those who were low on this measure $(M$ $=3.00, S E=0.13), F(1,63)=5.01, p=0.029, \eta_{p}^{2}=0.073$. On the other hand, in the low threat condition, the compensatory judgment did not significantly affect the perceived legitimacy of the current social system $(M \mathrm{~s}=3.06$ and $3.34, S E \mathrm{~s}=$ 0.12 and 0.12 , for those who were high and low on a measure of compensation, respectively), $F(1,102)=2.06, n s^{2}{ }^{2}$ The results were in line with Hypothesis 2 that people would more likely rely on the system-justifying function of compensatory judgments in the face of threats to their belief in the equality of the current society. One may at least say that compensatory judgments in person perception are capable of restoring one's sense of equality.

\section{Discussion}

In recent years, it has been demonstrated that person or group evaluation based on two fundamental dimensions (i.e., competence and warmth) tends to be ${ }^{2}$ To confirm that the perceived credibility did not differ between the two types of articles (high-threat vs. low-threat), the scores on the article credibility were subjected to a 2 (equality-threat condition: high vs. low) $\times 2$ (target competence: high vs. low) ANOVA. As a result, the main effect of the equality-threat condition was significant $\left(F(1,169)=6.06, p=0.015, \eta_{p}^{2}=\right.$ $0.035)$, indicating that the article stating that economic inequality existed in Japan $(M=4.39)$ was judged as more credible than the one stating that it did not $(M=3.84)$. Accordingly, we re-conducted a GLM analysis adding the article credibility as a covariate. Although the article credibility had the marginally significant effect on the perceived legitimacy, $F(1,164)=3.10, p=0.080$, $\eta_{p}^{2}=0.019$, the pattern of results as well as the significance level did not change substantially ( $F(1$, $164)=5.54, p=0.020, \eta_{p}^{2}=0.033$ for the interaction effect between the equality-threat condition and the compensatory judgment). 


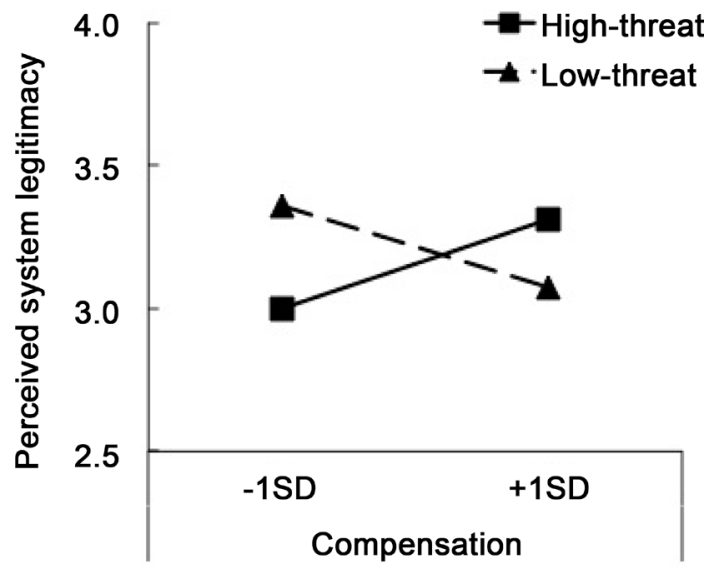

Figure 1. Simple effects of compensatory judgments on system legitimacy as a function of equality condition.

compensatory such that the target evaluated high on one of the two dimensions would be evaluated low on the other dimension (Judd et al., 2005; Yzerbyt et al., 2008). The present research addresses when and why such compensatory judgments emerge in person perception from the perspective of system justification theory (Jost \& Banaji, 1994) combined with the arguments made by Kay et al. (2007) regarding the system-justifying function of complementary stereotypes.

In our study, we examined whether individuals will make compensatory judgments in person perception in order to justify an economically unequal society. We theorized that the compensatory judgments based on competence and warmth would buffer against threats to the belief in equality through creating an illusion of equality. Specifically, we manipulated the levels of threat to equality in Japanese society by using fictional articles commenting on the economic disparity in Japan and examined whether a threat to the belief in equality motivated participants to make compensatory judgments and rely on the system-justifying function (i.e., the function of creating an illusion of equality) of compensatory judgments. Unfortunately, we did not obtain any evidence to support our prediction that compensatory judgments should more likely occur when participants are led to believe that a significant (relative to non-significant) economic disparity exists in Japan. However, it was shown that the positive relationship between the tendency of compensatory judgments and the level of perceived legitimacy of Japan's current social system became more conspicuous when participants were led to believe that a significant (relative to non-significant) economic disparity existed. This suggests that participants were more motivated to rely on the system-justifying function of complementary stereotypes, that is, the function of creating an illusion of equality, in the face of threats to their beliefs in equality in Japan. In other words, one could argue that the compensatory judgments in person perception serve as an effective means of restoring the impaired sense of equality and defend their perceived legitimacy of the current social system.

The relationships between system justification and complementary stereo- 
types have been studied by several researchers. These previous studies demonstrated that social judgments consistent with complementary stereotypes were instigated in the face of system threats induced by such messages as that the current social systems were insecure and ill-functioning (Jost et al., 2005; Kay et al., 2005). One should note that these messages did not refer to or comment on the issues of inequality in the current society. It therefore remained unclear whether participants were actually motivated to create an illusion of equality (to restore their sense of equality) through activating the complementary stereotypes and, hence, making compensatory judgments. The current study is advantageous on this point because we directly manipulated the participants' perception of equality of the current society and successfully showed that a threat to their beliefs in equality instigated the system-justifying function of compensatory judgments. The current results support our notion that compensatory judgments in person perception can maintain or defend the perceivers' sense of equality and, hence, contribute to justification of their current social system that yields economic inequality.

Another advantage of this study is that it suggests that people will actively generate an exemplar that is consistent with complementary stereotypes for system justification. Kay and Jost (2003) showed that exposure to complementary exemplars (vs. non-complementary exemplars) enhanced the perceived legitimacy of the social system. Unlike the study by Kay and Jost (2003), our participants were provided with diagnostic information only about the target's competence and not about the target's warmth. The participants, therefore, had to subjectively make up for scarce and ambiguous information in order to evaluate the target's warmth. They could have evaluated the target in either a compensatory or non-compensatory manner. The fact that compensatory judgments were associated with system justification only when the current Japanese society was perceived as unequal implies that they were more motivated to create an illusion of equality by generating a complementary exemplar when forming an impression of an individual. These findings suggest that the way of forming an impression of a certain individual is possibly determined by a macro structure of society. However, we admit that we should be cautious regarding this causational conclusion because it could be the case that positive evaluation of one's own social system leads one to make such compensatory judgments.

\subsection{Limitation}

Although some important contributions are described above, there remains an unresolved question: we failed to obtain evidence for our prediction that the amount of compensatory judgments should increase when faced with facts against the egalitarian worldview. From the current results, we cannot conclude that a threat to the social equality directly determines how impressions of others are formed (i.e., compensatory vs. non-compensatory). One possible reason for this is that the perception of economic inequality did not uniformly motivate 
every participant to make a compensatory impression. In order for a threat to societal equality to operate as a threat to legitimacy of that society, it is a prerequisite that perceivers endorse the egalitarian norm advocating that all human beings are equal and that a society without status hierarchy is ideal. In our study, it was unclear whether all the participants equally endorsed egalitarian norms in terms of economy and we cannot deny the possibility that individual differences in endorsement of egalitarian norms muddied the effects. Future studies must measure and control for the degree to which participants believe in the egalitarian norms.

\subsection{Future Direction}

It is important to note that the legitimacy should be defined in terms of more than one dimension. In other words, some evaluate the legitimacy based on equality (i.e., equal amounts to each person) while others evaluate it on equity (i.e., proportionate amounts to each person on the basis of his/her inputs) (e.g., Mitchell, Tetlock, Mellers, \& Ordonez, 1993). From the perspective of equity norms, the person who possesses a great ability to achieve an excellent outcome may be considered to deserve a high evaluation on warmth, which is a central and crucial personality dimension. If so, those who embrace equity norms are inclined to exhibit a stronger tendency of non-compensatory judgments (i.e., halo effects) about a competent or incompetent person they encounter and such psychological processes are more likely instigated when they are informed that the society is economically equal-every person enjoys an equal amount of reward regardless of his/her contribution-because this violates equity norms. In such situations, non-compensatory judgments rather than complementary judgments should presumably serve as a system-justifying device.

In line with the above argument, Kay, Czaplinski, and Jost (2009) revealed that the effect of complementary exemplars, depicted as rich but unhappy or as poor but happy, on system justification is moderated by the perceivers' political orientation. To be specific, exposure to complementary exemplars served as system justification for leftists (or liberals), whereas exposure to non-complementary exemplars (i.e., rich and happy or poor and unhappy) did the same for rightists (or conservatives). Their explanation was that left-wingers are inclined to make external attributions for failure and success, whereas right-wingers are inclined to make internal attributions. It can be interpreted instead that leftists tend to regard the equality norm as most important as the basis for justice, while rightists tend to regard the equity norm as most important.

In future studies, the multidimensionality of social justice should be taken into account to investigate which type of judgment (compensatory vs. non-compensatory) serves to justify the current social systems.

\subsection{Concluding Remarks}

This study is the first to provide direct experimental evidence for the relation- 
ship between system justification and compensation effects in person perception based on two fundamental dimensions of social judgments. We revealed that the compensatory judgments that emerged when forming an impression of a newly introduced person are capable of creating an illusion of equality that justifies the current social system, which yields significant and illegitimate economic disparity. Although a general tendency to perceive others in the compensatory manner based on the two fundamental dimensions of social judgments have been recurringly observed, it remained unclear how and why such effects emerge. Our study provides a clue to understand the underlying mechanisms and the social function of the compensatory effects. This is the main contribution of the present study. Moreover, our results indicate that people can easily accept the unjust status quo through the way of changing their style of impression formation in everyday life. Such psychological mechanisms may hinder one's willingness to change a problematic status quo. Understanding the processes through which an overarching social system is justified will lead us to uncover impediments to system change motivation and find ways to encourage people to reform their society.

\section{References}

Cuddy, A. J. C., Fiske, S. T., \& Glick, P. (2008). Warmth and Competence as Universal Dimensions of Social Perception: The Stereotype Content Model and the BIAS Map. In M. P. Zanna (Ed.), Advances in Experimental Social Psychology (Vol. 40, pp. 61-149). New York, NY: Academic Press.

Cutright, K. M., Wu, E. C., Banfield, J. C., Kay, A. C., \& Fitzsimons, G. J. (2011). When Your World Must Be Defended: Choosing Products to Justify the System. Journal of Consumer Research, 38, 62-77. https://doi.org/10.1086/658469

Fiske, S. T., Cuddy, A. J. C., \& Glick, P. (2007). Universal Dimensions of Social Cognition: Warmth and Competence. Trends in Cognitive Sciences, 11, 77-83.

https://doi.org/10.1016/j.tics.2006.11.005

Hennes, E. P., Nam, H. H., Stern, C., \& Jost, J. T. (2012). Not All Ideologies Are Created Equal: Epistemic, Existential, and Relational Needs Predict System-Justifying Attitudes. Social Cognition, 30, 669-688. https://doi.org/10.1521/soco.2012.30.6.669

Ikegami, T. (2006). What Does the Compensatory Judgment in Person Perception Signify? From the System Justification Perspective. [Taijin ninnchi no souhosei ha nani wo imi suruno ka: System justification tono kanren.] The 47 th Annual Meeting of Japanese Society of Social Psychology, 78-79. (In Japanese)

Jost, J. T., \& Banaji, M. R. (1994). The Role of Stereotyping in System-Justification and the Production of False Consciousness. British Journal of Social Psychology, 33, 1-27.

Jost, J. T., \& Hunyady, O. (2005). Antecedents and Consequences of System-Justifying Ideologies. Current Directions in Psychological Science, 14, 260-265. https://doi.org/10.1111/j.0963-7214.2005.00377.x

Jost, J. T., Banaji, M. R., \& Nosek, B. A. (2004). A Decade of System Justification Theory: Accumulated Evidence of Conscious and Unconscious Bolstering of the Status Quo. Political Psychology, 25, 881-919.

Jost, J. T., Glaser, J., Kruglanski, A. W., \& Sulloway, F. J. (2003). Political Conservatism as Motivated Social Cognition. Psychological Bulletin, 129, 339-375. 
https://doi.org/10.1037/0033-2909.129.3.339

Jost, J. T., Kivetz, Y., Rubini, M., Guermandi, G., \& Mosso, C. (2005). System-Justifying Functions of Complementary Regional and Ethnic Stereotypes: Cross-National Evidence. Social Justice Research, 18, 305-333. https://doi.org/10.1007/s11211-005-6827-z

Judd, C. M., James-Hawkins, L., Yzerbyt, V., \& Kashima, Y. (2005). Fundamental Dimensions of Social Judgment: Understanding the Relations between Judgments of Competence and Warmth. Journal of Personality and Social Psychology, 89, 899-913. https://doi.org/10.1037/0022-3514.89.6.899

Kay, A. C., \& Jost, J. T. (2003). Complementary Justice: Effects of "Poor But Happy" and "Poor But Honest" Stereotype Exemplars on System Justification and Implicit Activation of the Justice Motive. Journal of Personality and Social Psychology, 85, 823-837. https://doi.org/10.1037/0022-3514.85.5.823

Kay, A. C., Czaplinski, S., \& Jost, J. T. (2009). Left-Right Ideological Differences in System Justification following Exposure to Complementary versus Noncomplementary Stereotype Exemplars. European Journal of Social Psychology, 39, 290-298. https://doi.org/10.1002/ejsp.500

Kay, A. C., Gaucher, D., Peach, J. M., Laurin, K., Friesen, J., Zanna, M. P., \& Spencer, S. J. (2009). Inequality, Discrimination, and the Power of the Status Quo: Direct Evidence for a Motivation to See the Way Things Are as the Way They Should Be. Journal of Personality and Social Psychology, 97, 421-434. https://doi.org/10.1037/a0015997

Kay, A. C., Jost, J. T., \& Young, S. (2005). Victim Derogation and Victim Enhancement as Alternate Routes to System Justification. Psychological Science, 16, 240-246. https://doi.org/10.1111/j.0956-7976.2005.00810.x

Kay, A. C., Jost, J. T., Mandisodza, A. N., Sherman, S. J., Petrocelli, J. V., \& Johnson, A. L. (2007). Panglossian Ideology in the Service of System Justification: How Complementary Stereotypes Help Us to Rationalize Inequality. In M. P. Zanna (Ed.), Advances in Experimental Social Psychology (Vol. 39, pp. 305-358). New York, NY: Academic Press.

Kraus, M. K., Piff, P. K., \& Keltner, D. (2009). Social Class, Sense of Control, and Social Explanation. Journal of Personality and Social Psychology, 97, 992-1004. https://doi.org/10.1037/a0016357

Laurin, K., Shepherd, S., \& Kay, A. C. (2010). Restricted Emigration, System Inescapability, and Defense of the Status Quo: System-Justifying Consequences of Restricted Exit Opportunities. Psychological Science, 21, 1075-1082. https://doi.org/10.1177/0956797610375448

Mitchell, G., Tetlock, P. E., Mellers, B. A., \& Ordonez, L. D. (1993). Judgments of Social Justice: Compromises between Equality and Efficiency. Journal of Personality and Social Psychology, 65, 629-639. https://doi.org/10.1037/0022-3514.65.4.629

Rosenberg, S., Nelson, C., \& Vivekananthan, P. S. (1968). A Multidimensional Approach to the Structure of Personality Impressions. Journal of Personality and Social Psychology, 9, 283-294. https://doi.org/10.1037/h0026086

Smith, R. H. (2000). Assimilative and Contrastive Emotional Reactions to upward and downward Social Comparisons. In J. Suls, \& L. Wheeler (Eds.), Handbook of Social Comparison: Theory and Research (pp. 173-200). New York, NY: Plenum. https://doi.org/10.1007/978-1-4615-4237-7_10

Yada, N., \& Ikegami, T. (2010). Effects of Priming of Concepts about Relationship on Compensation Effects in Person Perception: Mediating Role of Social Comparison-Based Emotions. [Kankeisei priming ga souhotekininnchi ni oyobosu eikyo: Kanjou no baikaikouka ni tyumoku shite.] In The Proceeding of the 51 th Annual Meeting 
of the Japanese Society of Social Psychology (pp. 418-419). (In Japanese)

Yada, N., \& Ikegami, T. (2012). An Investigation on Compensation Effects in Person Perception: Role of Social Comparison-Based Emotions. In Studies in the Humanities (Vol. 63, pp. 9-26). Bulletin of the Graduate School of Literature and Human Sciences, Osaka City University. (In Japanese)

Yada, N., \& Ikegami, T. (2014). Compensation versus Halo Effects in Competitive or Cooperative Social Settings: Mediation Effects of Social Comparison-Based Emotions. Urban Scope: E-Journal of the Urban-Culture Research Center, 5, 27-40. http://urbanscope.lit.osaka-cu.ac.jp/journal/vol.005.html

Yzerbyt, V. Y., Kervyn, N., \& Judd, C. M. (2008). Compensation versus Halo: The Unique Relations between the Fundamental Dimensions of Social Judgment. Personality and Social Psychology Bulletin, 34, 1110-1123. https://doi.org/10.1177/0146167208318602 